therapy or with loved ones. This project was funded by the generosity of the TS Shipman Trust.

\section{0-25 THE PRESSURE AND PRIVILEGE OF PROVIDING PALLIATIVE CARE PROFESSIONALLY TO FRIENDS, FAMILY AND COLLEAGUES}

Lottie Morris, Ben Harris. Hospice Isle of Man, Douglas, Isle of Man, UK

\subsection{6/bmjspcare-2017-hospice.25}

Background Previous research has found that palliative care staff find it distressing when patients with whom they have grown close die. Hospice staff at units serving geographically remote populations are likely to provide palliative care frequently for friends, family and colleagues.

Aims This mixed methods study was designed to (i) determine whether levels of burnout were higher in hospice staff who had provided care for a greater number of people they knew personally and (ii) explore professionals' experiences of providing this care.

Methods Fifty nine participants from two hospice units completed the Maslach Burnout Inventory and reported the number of patients they had cared for over the last year who were friends, family or colleagues. They also reported stressors they perceived as causing and protecting against burnout. Eight participants then took part in focus groups to explore their experiences of providing palliative care for people they knew personally.

Results $>75 \%$ of participants had provided care for people they knew personally in the last year $($ Mean=4.4). Burnout scores were low and there was no relationship between burnout and the number of patients staff had known personally over the last year. While participants reported stressful aspects of caring for people they knew, particularly pressure to 'get it right', time pressures and team conflict were more consistently implicated in burnout. Factors such as sense of privilege, selfcare, and support from colleagues acted as a buffer against burnout.

Conclusions Levels of burnout in staff providing end of life care are low. Where burnout does occur, it is more likely to be caused by organisational issues rather than any aspect of caring for patients. The emotional toll and pressure of providing palliative care to family, friends and colleagues is mitigated by a range of protective factors. By drawing on coping strategies, this is often an intensely rewarding experience.

Acknowledgement This study was funded by the Isle of Man Research Committee.

\section{0-26 DEALING WITH THE 'DIFFICULT STUFF', WORKING IN A NON-CLINICAL TEAM IN A UK HOSPICE}

Fran Hyde. University of Essex, Colchester, UK

10.1136/bmjspcare-2017-hospice.26

Negotiating the changing health and social care environment has required hospices to recruit individuals to carry out specific roles which are not formed around clinical and caring responsibilities (Hospice UK, 2017). An individual joining a hospice may have expertise in digital marketing and social media but is unlikely to have detailed knowledge of end of life care. Whilst their role may require that they engage with and represent the day to day work of a hospice, unlike those performing clinical and caring roles, the individuals and the team at the centre of this study carried out their day to day work away from day centres or inpatient units. Whilst several studies have illuminated the work and challenges of clinical and care workers at hospices, little is known about the experiences of these other individuals and teams working away from patients and families but who together with clinical teams comprise and at times embody a modern hospice (Baugher, 2015; Bennet \& Barkensjo, 2005; Cain, 2012). Based on a three-month ethnographic study of a marketing team in a UK hospice which included participant observation and interviews, this study is important for trustees, senior leadership and clinical teams detailing the experiences of those working in hospices but away from patients and families. This study considers how individuals in a marketing team came to understand and find their own way to engage with the 'difficult stuff' (Georgia, 2015) at the heart of a hospice. At times understanding the challenging work of their hospice through BBC dramas such as 'The C Word' (Lucy, 2015) or their own families' experiences of hospice care the team were also concerned that those on the clinical side might regard their team as 'sitting in a cosy ivory tower' (Nina, 2015). Emerging themes from this study consider how a non-clinical team makes sense of a UK hospice.

\section{0-27 REHABILITATION PROVISION ACROSS UK HOSPICE SERVICES}

${ }^{1}$ Lucy Fettes, ${ }^{2}$ Helena Talbot-Rice, ${ }^{2}$ Gail Preston, ${ }^{1}$ Alanah Wilkinson, ${ }^{1}$ Fliss EM Murtagh, 1Irene J Higginson, 1,3 Lynne Turner-Stokes, 1,35tephen Ashford, "Matthew Maddocks. ${ }^{1}$ Cicely Saunders Institute, King's College London, London, UK; ${ }^{2}$ St Christopher's Hospice, London, UK; ${ }^{3}$ Regional Hyper-acute Rehabilitation Unit, London, UK

\subsection{6/bmjspcare-2017-hospice.27}

Background Rehabilitation is a key component of multi-professional palliative care. The provision of rehabilitation across hospice services falls outside national audit and is underresearched and therefore poorly understood.

Aim To describe the therapy input and interventions provided to patients attending UK hospice rehabilitation services, across inpatient and outpatient settings.

Methods Adults with advanced progressive disease were recruited to a multisite observational study examining the use of goal setting in routine rehabilitation practice, across 10 nationally representative hospices. Baseline demographics, allied health professional (AHP) involvement and therapy interventions were recorded, then compared according to setting using chi-squared or Mann Whitney $U$ tests as appropriate. Therapy interventions were ranked for each setting.

Results 239 patients (46\% male, mean (SD) age 68 (15) years) from outpatient $(n=141)$ and inpatient $(n-98)$ settings took part. The majority $(72 \%)$ had a primary cancer diagnosis and a stable phase of illness (70\%). Inpatients received more therapy input compared to outpatients with a greater number of AHPs involved (median [IQR] 2 [1-3] vs. 1 [1-2], p<0.001), more frequent involvement from occupational therapists $(56 \%$ vs. $27 \%, \mathrm{p}<0.001)$ and rehabilitation assistants $(51 \%$ vs. $30 \%$, $\mathrm{p}=0.001)$, and more therapy interventions being provided during an episode of care (median [IQR] 4 [2-6] vs. 2 [1-4], $\mathrm{p}<0.001)$. The type of therapy intervention(s) also differed according to setting (Table 1). 


\begin{tabular}{lllll}
\multicolumn{4}{l}{ Abstract 0-27 Table 1} \\
\hline Rank & Inpatients & $\begin{array}{l}\text { \% of patients } \\
\text { received }\end{array}$ & Outpatients & $\begin{array}{l}\text { \% of patients } \\
\text { received }\end{array}$ \\
\hline 1 & Mobility & 73 & Exercise programme & 71 \\
2 & Transfer practice & 55 & Mobility & 47 \\
3 & $\begin{array}{l}\text { Equipment/aid } \\
\text { provision }\end{array}$ & 48 & $\begin{array}{l}\text { Breathlessness } \\
\text { management }\end{array}$ & 36 \\
4 & Exercise & 45 & Fatigue management & 18 \\
& programme & & Equipment/aid & 16 \\
5 & Stairs practice & 30 & provision & \\
\hline
\end{tabular}

Conclusion Within UK hospice rehabilitation services, greater therapy input is typically provided to inpatients as compared to outpatients within each episode of care. The type of therapy intervention also appears to be setting dependant, with inpatient therapy focusing on basic mobility and other functional tasks and outpatient therapy on exercise and supported self-management.

\section{Poster presentations}

\section{Bereavement, loss and grief}

\section{P-1 'REMEMBERING DOESN'T HAVE TO BE SAD': GRANT FUNDED HOSPICE ACTIVITY DAYS AND WEEKENDS FOR TEENAGERS, CHILDREN AND FAMILIES}

Sarah Wardell, Sarah Popplestone-Helm. St Richard's Hospice, Worcester, UK

10.1136/bmjspcare-2017-hospice.28

The need for bereavement support in adult hospices for bereaved children and young people continues to grow. The hospice family support service has recorded an increase of $232 \%$ over a two year period in referrals for bereavement group support for families bereaved by expected, sudden and unexpected death within the local community. A new way of managing this increase in referrals was developed and has been trialled over a two year period. Teenage Activity Days and Children and Family Activity Weekends have been developed, offering additional support options for bereaved families. The aims of these groups are to improve emotional wellbeing, improve family relationships and enable families to learn positive coping strategies. These innovative groups provide an alternative means of support. The Teenage Activity Day addresses the gap previously present in group support for teenagers, focusing on developing communication with others through outdoor group activities whilst telling their story. The Children and Family Activity Weekend enables younger children to attend with a parent or carer who remains with them throughout the weekend; working on communication between the child/ren and parent/carer building their relationship following the bereavement, this also includes team building exercises such as climbing and kayaking in an outdoor arena. Following a pilot of both events in 2016, a bid was submitted to the small grants section of the BBC Children In Need fund to cover four more events in 2017 - this was successful and funding was secured. The first weekend in 2017 has taken place, demonstrating benefit for the whole family. Feedback has been very positive: 'It was awesome' 'I don't feel as shy now; I've met other children who feel the same as me' 'Remembering doesn't have to be sad' These one-off events for families promote communication and relationship building within the family whilst addressing the key issues surrounding the bereavement.

\section{P-2 BRIDGING THE GAP - CREATION OF A LIFESPAN BEREAVEMENT SERVICE}

Jane Hazeldine. Earl Mountbatten Hospice, Isle of Wight, UK

\subsection{6/bmjspcare-2017-hospice. 29}

The gap Together with our partners, the CCG and the LA, we recognised a need for open access children's bereavement services which offered wide-ranging and well-tailored support to bereaved children and their families. A significant gap also existed in professional support for parents of bereaved children. The Service The broad-based service we developed encompasses art, drama and music therapy alongside traditional talking and family therapy. These now link seamlessly with hospice-run adult bereavement services to offer a single, lifespan, open-access service for any bereaved child or family member. We now offer groups where psychologists, music therapists and community artists provide monthly individual and group sessions for children and their families and weekly groups for children where they can access art, drama and music, and meet other children in a similar position. We operate responsively and liaise with parents, teachers and mental health services and gather service-user feedback to monitor quality.

Outcomes and Demand We have noticed a significant and increasing demand for these new services. Our referrals have increased significantly and these also now come from a greater variety of sources as more schools and external services become aware. Results show that services of this type are important and necessary and that there is significant demand for such a responsive, multi-faceted and well-resourced project. In particular we are finding that the lack of service boundaries and the seamless linkages across traditional age barriers are very well evaluated. We will continue to expand the service in line with demand and are proud of what we have achieved. We will be highlighting the process and challenges of service setup and explain how partnership working has been vital to success. Results of our ongoing evaluation will also be presented.

\section{P-3 THE BEREAVEMENT JOURNEY: MAKING THE RIGHT CONNEXIONS}

Julia Russell, Rebecca Trower, Anne Cullen. Princess Alice Hospice, Surrey, UK

\subsection{6/bmjspcare-2017-hospice.30}

Background This poster presents a hospice project to improve support for bereaved people, through an integrated approach across Bereavement, Fundraising and Communications departments.

Aims User feedback, evaluations and research showed that: People needed more continuity of support in early bereavement. We need to make it easier for people to access information about commemorating their loved one, though physical 